\title{
Detection of self-incompatible oilseed rape plants (Brassica napus L.) based on molecular markers for identification of the class I $S$ haplotype
}

\author{
Lenka Havlícková ${ }^{1}$, Eva Jozová ${ }^{1}$, Miroslav Klíma ${ }^{2}$, Vratislav Kucera ${ }^{2}$ and Vladislav Curn ${ }^{1}$ \\ ${ }^{1}$ Biotechnological Centre, Faculty of Agriculture, University of South Bohemia, Ceské Budejovice, \\ Czech Republic. \\ ${ }^{2}$ Crop Research Institute, Praha, Czech Republic.
}

\begin{abstract}
The selection of desirable genotypes with recessive characteristics, such as self-incompatible plants, is often difficult or even impossible and represents a crucial barrier in accelerating the breeding process. Molecular approaches and selection based on molecular markers can allow breeders to overcome this limitation. The use of self-incompatibility is an alternative in hybrid breeding of oilseed rape. Unfortunately, stable self-incompatibility is recessive and phenotype-based selection is very difficult and time-consuming. The development of reliable molecular markers for detecting desirable plants with functional self-incompatible genes is of great importance for breeders and allows selection at early stages of plant growth. Because most of these reliable molecular markers are based on discrimination of class I S-locus genes that are present in self-compatible plants, there is a need to use an internal control in order to detect possible PCR inhibition that gives false results during genotyping. In this study, 269 double haploid $\mathrm{F}_{2}$ oilseed rape plants obtained by microspore embryogenesis were used to verify the applicability of an improved PCR assay based on the detection of the class I SLG gene along with an internal control. Comparative analysis of the PCR genotyping results vs. $S$ phenotype analysis confirmed the applicability of this molecular approach in hybrid breeding programs. This approach allows accurate detection of self-incompatible plants via a different amplification profile.
\end{abstract}

Keywords: double haploid, hybrid breeding, MAS, S locus, SLG.

Received: November 21, 2013; Accepted: April 14, 2014.

An efficient pollination control system is necessary in hybrid breeding in order to avoid unwanted self-pollination or sib-pollination of the female parental line. In self-pollinating plants such programs are limited in their ability to overcome and prevent pollination by their own pollen. Consequently, hybrid breeding depends on a variety of approaches to protect maternal plants from self-pollination. Self-incompatibility (SI) prevents self-fertilization by rejecting pollen from plants with the same genotype (Charlesworth, 2010; Goring and Indriolo, 2010) and has been successfully used for seed production in $F_{1}$ hybrid cultivars of Brassica napus (Zhang et al., 2008a). In Brassica, the specificity of pollen-stigma interactions in SI systems is controlled sporophytically by two linked genes with multiple allelic forms ( $S$ haplotypes) of a single Mendelian polymorphic locus, designated as the $S$ locus (Bateman, 1955; Nasrallah et al., 1991). The male and female determinants of SI encoded by the $S$-locus genes have been identified as a peptide ligand (S-locus protein 11; SP11, or

Send correspondence to Lenka Havlícková. Biotechnological Centre, Faculty of Agriculture, University of South Bohemia, Studentská 13, Ceské Budejovice, CZ-370 05, Czech Republic. E-mail address: lenk@ post.cz.
$S$-locus cysteine-rich protein; $S C R$ ) (Schopfer et al., 1999; Suzuki et al., 1999) and its cognate receptor ( $S$-locus receptor kinase; SRK; Stein et al., 1991) respectively. Recognition specificity is achieved by interaction of the female determinant $S R K$ with its ligand, the male determinant SP11 (Chapman and Goring, 2010). The interaction between SP11 and SRK triggers the signaling cascade in an $S$-haplotype-specific manner and results in the rejection of self-pollen, but the signal components involved are still not well characterized (Zhang et al., 2011). S-locus glycoprotein (SLG) encoded by the $S L G$ gene is the second female determinant involved in SI reaction. SLGs accumulate in the mature papilla cell wall and affect selfpollen tube development (Kishi-Nishizawa et al., 1990). Gain-of-function experiments have demonstrated that SLG enhances the recognition reaction of SI (Watanabe et al., 2003).

The $S$ haplotypes are divided into classes I and II (Nasrallah et al., 1991). Class I is generally dominant over class II in pollen and confers a strong SI phenotype (Nasrallah and Nasrallah, 1993). Cultivated B. napus $(2 \mathrm{n}=38, \mathrm{AACC})$ is a self-compatible allotetraploid that originated through spontaneous interspecific hybridization between two self-incompatible species, Brassica rapa 
$(2 \mathrm{n}=20, \mathrm{AA})$ and Brassica oleracea $(2 \mathrm{n}=18, \mathrm{CC})$. Theoretically, $B$. napus lines are considered to be homozygous at two $S$ loci, with one $S$ haplotype being derived from $B$. rapa and the other from B. oleracea. Brassica napus is considered to be self-incompatible like its two ancestors and artificially produced lines, although most cultivated lines are self-compatible (Zhang et al., 2011). Most B. napus contain a class I $S$ haplotype (similar to $S^{47}$ of $B$. rapa) in the A genome and a class II haplotype (similar to $S^{15}$ of $B$. oleracea) in the $\mathrm{C}$ genome (Okamoto et al., 2007; Zhang et al., 2008a). Self-compatibility in B. napus is caused by independent mutations in dominant $S$ haplotypes that result in suppression of the functional recessive $S$ haplotype on different chromosomes (Okamoto et al., 2007). Four and three class-II $S$ haplotypes have been identified in B. rapa $\left(S^{29}\right.$, $\left.S^{40}, S^{44}, S^{60}\right)$ and B. oleracea $\left(S^{2}, S^{5}, S^{15}\right)$ (Sato et al., 2006). Not surprisingly, in homozygous plants with two recessive $S$ haplotypes, the character of the recessive $S$ haplotype appears as an SI phenotype that is usually a mutant phenotype. However, genetic changes in polyploid B. napus, including chromosomal rearrangements (Udall et al., 2005) and epigenetic phenomena (Gaeta et al., 2007; Zhang et al., 2011), can alter gene expression and phenotype. No original Czech hybrid cultivar based on SI has yet been released, but SI is currently intensively used in Czech breeding programs. An approach based on molecular marker technology for the genotyping of breeding populations in rapeseed hybrid breeding could provide a greater incentive for investment.

A double haploid (DH) SI line (SI20) with stable recessive $S$ haplotypes derived from crosses between an SI donor line (WRG15) and self-compatible donors of 00-quality (2051; Viking) and four self-compatible (SC) cultivars (Da Vinci, Cabernet, Chagall and Wisent) were used in this study (Figure 1). Four SC cultivars were used as the male parent in crosses with the SI20 line to obtain $F_{1}$ hybrids, and the $\mathrm{F}_{1}$ plants were used to produce $269 \mathrm{DH}$ of the $\mathrm{F}_{2}$ population via microspore embryogenesis. These populations are regularly created by breeders to improve the properties of self-incompatible plants and obtain desirable genotypes of comparable or excess properties equal to current best cultivars. The variation of newly created $\mathrm{DH}$ plants reflects primarily in additive gene effects and additive epistasis, enabling fixation in only one cycle of selection compared to about seven years using the conventional system to generate near homozygous lines. All of the materials used in this study were obtained from the Research Institute of Crop Production in Prague, Czech Republic.

The $S$ phenotype was measured as follows: when the first flowers appeared on the major inflorescence, this inflorescence and two secondary ramifications were bagged for self-pollination. Every two days, the bags were tapped gently to ensure enough self-pollination. The bags were removed after three weeks to allow the seeds to develop in a more natural environment. After maturation of the seed siliques, the number of seeds produced was counted. The seed set obtained by selfing was checked when siliques were ripe. Plants were considered as SI when the number of seeds per silique ranged from 0 to 3 . Self-seeds were obtained by bud-pollination when the SI reaction was still not fully developed.

Genomic DNA from B. napus cultivars and the DH line was extracted from young leaves using the cetyltrimethylammonium bromide (CTAB) method (Williams et al., 1992). The concentration and quality of DNA was determined with a BioMate 5 spectrophotometer. PCR amplification was done using a primer pair SLGa (Zhang et al., 2008b) developed from SLG-A10 and that amplified a $\sim 1100$ bp region in SC plants but not in the SI line. The primer pair $\mathrm{SCO} 3$ that amplified a $\sim 750 \mathrm{bp}$ fragment (Zeng

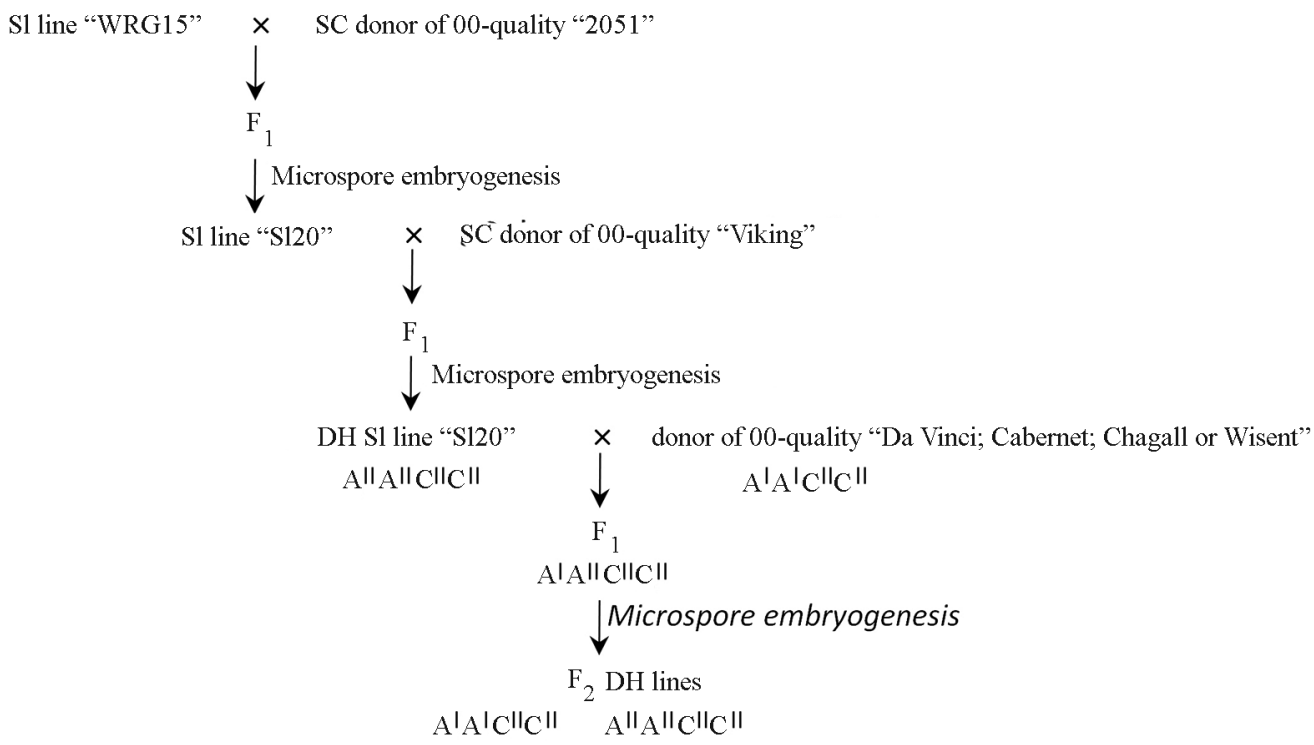

Figure 1 - Overview of the triple-cross model, including the three-component hybrid and three line hybrid in B. napus. 
Principle of genotyping by using the SLG 1 gene



Figure 2 - Phenotypic and genotypic screening of $\mathrm{F}_{2} \mathrm{DH}$ plants. The plants $(\mathrm{n}=269)$ initially underwent $S$ phenotypic analysis followed by genotyping with molecular markers. Duplex PCR with class I SLG-specific primers (SLGa forward and reverse) resulted in the amplification of an $\sim 1.1 \mathrm{~kb}$ fragment in plants considered to be self-compatible (SC); self-incompatible (SI) plants showed no such fragment. All samples (SC and SI) showed amplification of a 750-bp internal control fragment. $\mathrm{M}$ - molecular markers.

et al., 2009) was used as a positive control for the presence of DNA in the PCR. PCR was done with $10 \mathrm{ng}$ of genomic DNA as template, mixed with $0.5 \mu \mathrm{L}(10 \mu \mathrm{M})$ of each primer, $10 \mu \mathrm{L}$ of PPP master mix (TopBio), 1x BSA and distilled water to give a final volume of $20 \mu \mathrm{L}$. The PCR reaction involved pre-denaturation for $3 \mathrm{~min}$ at $95{ }^{\circ} \mathrm{C}$ followed by 35 cycles of $30 \mathrm{~s}$ at $94^{\circ} \mathrm{C}, 45 \mathrm{~s}$ at $58^{\circ} \mathrm{C}$ and $1 \mathrm{~min}$ at $72{ }^{\circ} \mathrm{C}$ and finally, $10 \mathrm{~min}$ at $72{ }^{\circ} \mathrm{C}$. The PCR products were subjected to electrophoresis on $1.5 \%$ agarose gels in 1x Tris-borate-EDTA (TBE) buffer and detected by staining with ethidium bromide.

All SI20 x (SC) Da Vinci, Cabernet, Chagall and Wisent $F_{1}$ plants were completely self-compatible, indicating that the $S$ haplotype of the A genome of SI20 was recessive $\left(\mathrm{A}^{\mathrm{II}} \mathrm{A}^{\mathrm{II}} \mathrm{C}^{\mathrm{II}} \mathrm{C}^{\mathrm{II}}\right.$ ) to four $\mathrm{SC}$ cultivars deduced to be $\mathrm{A}^{\mathrm{I}} \mathrm{A}^{\mathrm{I}} \mathrm{C}^{\mathrm{II}} \mathrm{C}^{\mathrm{II}}$. Self-incompatibility was assessed in the $\mathrm{F}_{2} \mathrm{DH}$ population of 269 plants. The distribution of the $\mathrm{S}$ phenotype showed two distinct classes, with a score $<3$ indicating SI plants $(\mathrm{n}=119)$ and $>10$ indicating SC plants $(\mathrm{n}=113)$. Limited number of plants $(n=37)$ showed intermediate character with score 4-10 indicating SI/SC plants. The segregation of $\mathrm{SC}$ plants to SI plants in the $\mathrm{F}_{2} \mathrm{DH}$ population at the molecular level agreed with the expected ratio of 1:1 (130 SC vs. 139 SI) for a single $S$ locus (Figure 2).

An approach based on molecular markers was implemented in a traditional schedule of oilseed rape hybrid breeding. A particular technique that involved two pairs of primers was used to manage the breeding population. Comparison of the genotype (presence of the desired alleles) vs. phenotype (seed test) showed that selection based only on phenotypic expression (number of seeds per silique) can lead to the loss of valuable SI genotypes (in our case, with improper selection $4.5 \%$ of the plants $(n=12)$ would be excluded, as well as a further 37 phenotypically indistinguishable flowers, if there were no subsequent molecular characterization). In 12 plants phenotypically identified as $\mathrm{SC}$ we assumed that there was breakdown of the SI barrier at the end of flowering, possibly as a result of survival strategies. The 17 plants that showed the SI phenotype (contrary to their SC genotype) could have been caused by high tem- peratures in the pollination bags that, together with humidity, can lead to complete sterility (Shah et al., 2011) or induce the loss of siliques in the early stages of development, as described by Young et al. (2004). The presence of haploid plants can also cause the SI phenotype.

Recent molecular screening for the class I $S$ haplotype has been based on the detection of SLG I/SRK I genes (Gao et al., 2013), and gene transformation studies have confirmed that both of these genes are important for the SI recognition reaction (Watanabe et al., 2012). Self-incompatibility mechanisms associated with functional molecular markers can be particularly important in hybrid breeding, as suggested by Tochigi et al. (2011). These authors showed that the use of a molecular marker based selection of SI plants leads to elimination of undesirable SC plants at an early ontogenetic stage and to favourable reduction of the number of plants available for subsequent experiments. In conclusion, the results of this study indicate that we have successfully developed and validated a new approach for detecting SI.

\section{Acknowledgments}

This research was supported by projects QI111A075, GAJU 063/2013/Z and project Postdoc USB no. CZ.1.07/2.3.00/30.0006. We thank Dr. E.A. Merkulova for reading the manuscript and helpful comments.

\section{References}

Bateman AJ (1955) Self-incompatibility systems in angiosperms: III, Cruciferae. Heredity 9:52-58.

Chapman LA and Goring DR (2010) Pollen-pistil interactions regulating successful fertilization in the Brassicaceae. J Exp Bot 61:1987-1999.

Charlesworth D (2010) Self-incompatibility. Biol Rep 2:68.

Gaeta RT, Pires JC, Iniguez-Luy F, Leon E and Osborn TC (2007) Genomic changes in resynthesized Brassica napus and their effect on gene expression and phenotype. Plant Cell 19:3403-3417.

Gao C, Ma C, Zhang X, Li F, Zhang J, Zhai W, Wang Y, Tu J, Shen $\mathrm{J}$ and $\mathrm{Fu} \mathrm{T}$ (2013) The genetic characterization of 
self-incompatibility in a Brassica napus line with promising breeding potential. Mol Breed 31:485-493.

Goring D and Indriolo E (2010) How plants avoid incest. Nature 466:296-928.

Kishi-Nishizawa N, Isogai A, Watanabe M, Hinata K, Yamakawa S, Shojima S and Suzuki A (1990) Ultrastructure of papilla cells in Brassica campestris revealed by liquid helium rapid freezing and substitution-fixation method. Plant Cell Physiol 31:1207-1219.

Nasrallah JB and Nasrallah ME (1993) Pollen-stigma signaling in the sporophytic self-incompatibility response. Plant Cell 5:1325-1335.

Nasrallah JB, Nishio T and Nasrallah ME (1991) The self-incompatibility genes of Brassica: Expression and use in genetic ablation of floral tissues. Annu Rev Plant Physiol Plant Mol Biol 42:393-422.

Okamoto S, Odashima M, Fujimoto R, Sato Y, Kitashiba H and Nishio T (2007) Self-compatibility in Brassica napus is caused by independent mutations in $S$-locus genes. Plant $\mathrm{J}$ 50:391-400.

Sato Y, Sato K and Nishio T (2006) Interspecific pairs of class II $S$ haplotypes having different recognition specificities between Brassica oleracea and Brassica rapa. Plant Cell Physiol 47:340-345.

Schopfer CR, Nasrallah ME and Nasrallah JB (1999) The male determinant of self-incompatibility in Brassica. Science 286:1697-1700.

Shah F, Huang J, Cui K, Nie L, Shah T, Chen C and Wang K (2011) Impact of high-temperature stress on rice plant and its traits related to tolerance. J Agr Sci 149:545-556.

Stein JC, Howlett B, Boyes DC, Nasrallah ME and Nasrallah JB (1991) Molecular cloning of a putative receptor protein kinase encoded at the self-incompatibility locus of Brassica oleracea. Proc Natl Acad Sci USA 88:8816-8820.

Suzuki G, Kai N, Hirose T, Fukai K, Nishio T, Takayama S, Isogai A, Watanabe M and Hinata K (1999) Genomic organization of the $S$ locus: Identification and characterization of genes in $S L G / S R K$ region of $S(9)$ haplotype of Brassica campestris (syn. rapa). Genetics 153:391-400.
Tochigi T, Udagawa H, Li F, Kitashiba H and Nishio T (2011) The self-compatibility mechanism in Brassica napus $\mathrm{L}$. is applicable to F1 hybrid breeding. Theor Appl Genet 123:475-482.

Udall JA, Quijada PA and Osborn TC (2005) Detection of chromosomal rearrangements derived from homologous recombination in four mapping populations of Brassica napus L. Genetics 169:967-979.

Watanabe M, Takayama S, Isogai A and Hinata K (2003) Recent progresses on self-incompatibility research in Brassica species. Breed Sci 53:199-208.

Watanabe M, Suwabe K and Suzuki G (2012) Molecular genetics, physiology and biology of self-incompatibility in Brassicaceae. Proc Jpn Acad Ser B 88:519-535.

Williams JGK, Hanafey MK, Rafalski JA and Tingey SV (1992) Genetics analysis using RAPD markers. Methods Enzymol 260:335-348.

Young LW, Wilen RW and Bonham-Smith PC (2004) High temperature stress of Brassica napus during flowering reduces micro- and megagametophyte fertility, induces fruit abortion, and disrupts seed production. J Exp Bot 55:485-495.

Zeng F, Yi B, Tu J and Fu T (2009) Identification of AFLP and SCAR markers linked to the male fertility restorer gene of pol CMS (Brassica napus L.). Euphytica 165:363-369.

Zhang X, Ma C, Tang J, Tang W, Tu J, Shen J and Fu T (2008a) Distribution of $S$ haplotypes and its relationship with restorer-maintainers of self-incompatibility in cultivated Brassica napus. Theor Appl Genet 117:171-179.

Zhang X, Ma C, Fu T, Li Y, Wang T, Chen O, Tu J and Shen J (2008b) Development of SCAR markers linked to selfincompatibility in Brassica napus L. Mol Breed 21:305315.

Zhang X, Yin D, Zhu W, Ma C and Fu T (2011) Progress on characterization of self-incompatibility in Brassica napus L. Euphytica 182:147-155.

\section{Associate Editor: Dario Grattapaglia}

License information: This is an open-access article distributed under the terms of the Creative Commons Attribution License, which permits unrestricted use, distribution, and reproduction in any medium, provided the original work is properly cited. 